\title{
Breast cancer survivorship in an Asian specialist centre from Malaysia: A retrospective analysis
}

\author{
Azura Rozila Ahmad', Jia Shin Jessica Tan², Arkonam Balasubramaniam Manivannan ${ }^{3}$, \\ Mohamed Ibrahim A. Wahid ${ }^{3}$
}

${ }^{1}$ Consultant Medical Oncologist, ${ }^{3}$ Consultant Clinical Oncologist, Department of Oncology; ${ }^{2}$ Clinical Informatics Specialist, Clinical Research Department, Beacon Hospital, Petaling Jaya, 46050 Selangor, Malaysia

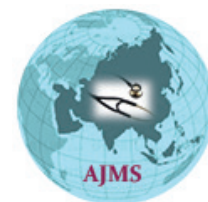

\section{A B S T R A C T}

Background: Real world data (RWD) is increasingly relevant in breast cancer (BCa) as it is the most frequently diagnosed cancer. Developed world has seen improved breast cancer survival, however, RWDon BCa survival in Malaysia is still lacking. Aims and Objectives: This study aims to determine characteristics and survival of $\mathrm{BCa}$ patients from a single institute. Materials and Methods: Retrospective analysis of $168 \mathrm{BCa}$ patients who were treated with at least one treatment modality in Beacon International Specialist Centre (BISC) from 2008-2012 was conducted. Patient characteristicsand treatments received were analysed descriptively to survival outcome.Vital status was obtained from the National Registry of Birth and Death (NRD) records. Observed survival rates wereestimated by Kaplan-Meier method and difference between groups by log-rank. Results: Of 143 eligible BCa patients, 28 (19.6\%) died during the study period. Five-year BCa specific survival rates were $100 \%$ for Stage I and II, $79.31 \%$ for stage III and $38.89 \%$ for Stage IV disease. In the multivariate analysis, higher stage at diagnosis, triple negative breast cancer with metastases and higher grade were associated with worse survival outcomes. The overall 5 -year survival rate of BCa patients in BISC from 2008-2012 compares favourably to the survival data of developed countries. Conclusion: In conclusion, the overall 5-year survival rate of BCa patients in BISC compares favourably to the survival data of developed countries, as well as to other institutions.

Access this article online

Website:

http://nepjol.info/index.php/AJMS DOI: 10.3126/ajms.v10i6.25885 E-ISSN: 2091-0576

P-ISSN: 2467-9100

Key words: Breast cancer; Survival outcome; Real world data; Malaysia; Triple negative breast cancer; 5-year survival of Breast Cancer

\section{INTRODUCTION}

Breast cancer is the most common cancer affecting Malaysian women and is the most common cancer-related mortality in women worldwide. ${ }^{1}$ The breast cancer incidence and survival rates were reportedly lower in Eastern Asia in contrast to developed countries. Besides, recent Asian studies indicated that the annual incidence of breast cancer have doubled over the past two decades ${ }^{2,3}$ though studies from the Western countries have reported otherwise. ${ }^{3,4}$

Breast cancer has a high survival rate when detected early and given appropriate treatment. ${ }^{5}$ Despite the dramatic variation between populations, ${ }^{6}$ generally, breast cancer patient outcomes have improved substantially over the years. Currently, age standardized relative survival at 5 years is recorded at $>80 \%$ for developed countries including Japan, North America, Sweden, Finland and Australia, in contrast to developing countries, where 5 -year survival rates are recorded at $<40-60 \%$.

To further understand the disease epidemiology and survival rates with respect to patient characteristics, treatment options and outcomes, observational studies are fundamental in providing valuable information. 
Real world data (RWD) is increasingly gaining attention for its pivotal role in health care related planning of diseases, particularly for breast cancer as it poses significant burden for women in Asia with reportedly the highest number of breast cancer cases $(53 \%)$ up to 2012. ${ }^{8}$ However, RWD on breast cancer and treatment outcomes remains limited in Malaysia to date. This study aims to describe patient characteristics and survival in real-world and to report improvement in 5-year overall survival of breast cancer using data obtained from Beacon Hospital $(\mathrm{BH})$, a private healthcare centre in Malaysia.

\section{MATERIALS AND METHODS}

\section{Study population}

We conducted a retrospective observational cohort study by examining the data on pathologically confirmed primary breast cancer patient who had received at least one treatment modality at Beacon Hospital, Petaling Jaya, Malaysia. All 168 breast cancer patients diagnosed from $1^{\text {st }}$ of January 2008 to $31^{\text {st }}$ of December 2012 were reviewed for this study. Identification of case was done through hospital registry with further data retrieved from past chemotherapy, radiotherapy records. Foreign patients, patients with non-epithelial malignancy or recurrent tumour were excluded from this study.

\section{Data collection}

Medical records as well as patient's histopathology reports (HPE) were extracted. Patient demography to include age, ethnicity and nationality; tumour characteristics to include size, grade, hormonal receptor status and staging; treatment patterns and survival were analysed descriptively. Staging of the disease was based on the American Joint Committee on Cancer (AJCC) criteria. The survival data of the patients at the end of the study period and the date of death were obtained from the medical records/National Registry of Birth and Death (NRD). Ethics approval was obtained from Medical Research Ethics Committee (MREC ID: NMRR-11-38-2814).

\section{Statistical analysis}

Statistical analyses were performed using MedCalc. The patient's characteristics were described by percentages. Kaplan-Meier analyses were conducted to estimate overall survival rates. The survival time of a patient is referred to the number of months from the date of diagnosis to the date of the death or the date of last follow-up. Log-rank test was used to compare survival distributions of different subgroups in our data. Two tailed $\mathrm{p}$ value of $<0.05$ was considered statistically significant.

\section{RESULTS}

Data from 168 patients were gathered for this study, of which only 143 were eligible for this study. Malaysian Chinese comprises $59.4 \%$ of the total patients, $32.1 \%$ were Malay and $7.7 \%$ were Malaysian Indians. Only 1 patient is from other ethnic groups. Patient demographic is presented in Table 1. The age of diagnosis was recorded from the first admission. The mean age of diagnosis was 53 years, with the youngest age of diagnosis recorded at 23 years. When categorized by stage, 22/36 (61\%) stage 4 patients were in menopausal age. Most of the patients presented with early breast cancer (52.7\%).The major histological subtype among patients were invasive ductal carcinoma (IDC), which makes up $86 \%$ of cases during the study period. In addition, most of the patients $(59.4 \%)$ were diagnosed with moderate to large tumour size $(\geq \mathrm{T} 2)$. $100 / 143(69.9 \%)$ of the enrolled patients were oestrogen receptor positive; $83 / 143(58 \%)$ were progesterone receptor positive; 42/143 (29.4\%) were HER2 positive; and $17.5 \%$ were Triple Negative.

From the 129 patients who underwent surgery, about half $(51.5 \%)$ of the patients underwent mastectomy and $37.8 \%$ opted for lumpectomy. For metastatic breast cancer patients, less than half $(44.4 \%)$ of the patients were undergoing first line chemotherapy, whereas $19.44 \%$ were on their second line chemotherapy with the remaining $(27.8 \%)$ had already received more than 2 lines of chemotherapy. Moreover, $7.5 \%$ of early stage or locally advanced breast cancer patients refused treatment whereas $11.1 \%$ of advanced stage patients refused palliative treatments. Meanwhile, $21.43 \%$ of patients (from both early stage and advanced stage) refused trastuzumab treatment despite diagnosed with HER2 positive. See Table 2 for treatment patterns amongst breast cancer patients who sought treatment at $\mathrm{BH}$.

The overall 5-year survival rate was $80.4 \%$, with a median overall 5-year survival of 75.93 months (95\% CI: 73.03483.546). Twenty-eight (19.6\%) breast cancer patient died during the study period. The overall survival was $100 \%$ at 5 years for both Stage I and stage II, 79.31\% for stage III and $38.89 \%$ for Stage IV disease (Figure 1a(i)) $(\mathrm{p}<0.0001)$.

The 5-year survival rates amongst three main ethnic groups observed that the Indian women recorded the highest survival rate $(81.82 \%)$, followed by Chinese women (81.18\%) and Malay (78.26\%) (Figure 1a(ii)) though not statistically significant $(\mathrm{p}=0.9604)$. We have also failed to detect any association between survival and age of diagnosis $(\mathrm{p}=0.493)$. In addition, our study has found that stage 4 patients in the $>50$ years age group has a better overall survival $(40.91 \%)$ when compared to 


\begin{tabular}{|c|c|}
\hline \multicolumn{2}{|c|}{ 1a. Patient demographic } \\
\hline Characteristics & Patients $(n=143)$ \\
\hline \multicolumn{2}{|l|}{ Age } \\
\hline Median (range) & $51(23-95)$ \\
\hline \multicolumn{2}{|l|}{ Ethnicity, n (\%) } \\
\hline Malay & $46(32.2)$ \\
\hline Chinese & $85(59.4)$ \\
\hline Indian & $11(7.7)$ \\
\hline Other & $1(0.7)$ \\
\hline \multicolumn{2}{|c|}{ 1b. Disease at presentation } \\
\hline Characteristics & Patients $(n=143)$ \\
\hline \multicolumn{2}{|l|}{ ECOG/PS, n (\%) } \\
\hline 0 & $46(32.2)$ \\
\hline 1 & $16(11.2)$ \\
\hline$\geq 2$ & $5(3.5)$ \\
\hline Unknown & $76(53.2)$ \\
\hline \multicolumn{2}{|l|}{ Stage at presentation, $\mathrm{n}(\%)$} \\
\hline IA-IB & $26(18.2)$ \\
\hline IIA-IIB & $49(34.3)$ \\
\hline$\|I A-\| I C$ & $29(20.3)$ \\
\hline IV & $36(25.2)$ \\
\hline \multicolumn{2}{|l|}{ Tumour size, n (\%) } \\
\hline $\mathrm{T} 1(\leq 20 \mathrm{~mm})$ & $58(40.6)$ \\
\hline $\mathrm{T} 2(20<\mathrm{T} \leq 50 \mathrm{~mm})$ & 67 (46.9) \\
\hline T3 $(<50 \mathrm{~mm})$ & $8(5.6)$ \\
\hline Unknown & $10(7.0)$ \\
\hline \multicolumn{2}{|l|}{ Regional nodes, $\mathrm{n}(\%)$} \\
\hline Negative & $69(48.3)$ \\
\hline Positive & $63(44.1)$ \\
\hline Unknown & $11(7.7)$ \\
\hline \multicolumn{2}{|l|}{ Tumour histology, n (\%) } \\
\hline Invasive breast carcinoma & $132(92.3)$ \\
\hline IDC & $123(86.0)$ \\
\hline ILC & $8(5.6)$ \\
\hline Mixed IDC/ILC & $1(0.7)$ \\
\hline Ductal carcinoma in situ & $3(2.1)$ \\
\hline Other carcinomas & $5(3.5)$ \\
\hline Unknown & $3(2.1)$ \\
\hline \multicolumn{2}{|l|}{ Grading, n (\%) } \\
\hline 1 & $8(5.6)$ \\
\hline 2 & $58(40.6)$ \\
\hline 3 & $61(42.7)$ \\
\hline Unknown & $16(11.2)$ \\
\hline \multicolumn{2}{|l|}{ Hormonal receptor status, $\mathrm{n}(\%)$} \\
\hline ER- and PR - & $38(26.6)$ \\
\hline $\mathrm{ER}+$ and/or PR+ & $102(71.3)$ \\
\hline HER2 & $42(29.4)$ \\
\hline Triple Negative & $25(17.5)$ \\
\hline Unknown & $9(6.3)$ \\
\hline Site of Metastasis, n (\%) & 36 \\
\hline Lung & $14(38.9)$ \\
\hline CNS & $12(33.3)$ \\
\hline Bone & $24(66.7)$ \\
\hline Liver & $16(44.4)$ \\
\hline Others & $10(27.8)$ \\
\hline Unknown & $1(2.8)$ \\
\hline Only 1 visceral organ & $16(44.4)$ \\
\hline$>1$ visceral organ & $6(16.7)$ \\
\hline
\end{tabular}

patients from the younger age group (28.57\%), however the difference is not statistically significant $(\mathrm{p}=0.9796)$. We also further stratified stage 4 patients by their hormonal status, particularly ER, and found that the survival outcome is similar (ER negative: $33.3 \%$ and ER positive: 37.5\%) regardless of their ER status ( $p=0.9831)$ Figure 1B.

On the other hand, we also investigated the survival outcome of the patients with triple negative breast cancer subtype, categorized by their metastasis status. Our study reported a 100\% 5-year overall survival in triple negative breast cancer patients without presence of metastasis, whereas triple negative breast cancer patients with the presence of metastasis recorded a $40 \%$ survival $(p=0.0004)$. (Figure 1c)

\section{DISCUSSION}

Breast cancer survival data are lacking in Malaysia. To date, there are only 3 institutional-based and one populational based studies were conducted within the country. ${ }^{9-11}$ Though breast cancer rates remain comparatively low amongst Asian women, a large body of scientific literature supports the notion that the breast cancer incidence has increased at an alarming rate in Asia. ${ }^{12,13}$ In addition, a higher mortalityto-incidence ratio, more aggressive disease at diagnosis and reduced survival were also observed in less developed countries when compared to more developed countries in Asia. ${ }^{14}$ Therefore, RWD is pivotal not only at providing an overall view on the breast cancer disease outcome and survival rate, but also to evaluate the effectiveness of treatment plans in a healthcare setting and to gain public confidence on cancer treatment in our country. In the current study, we evaluated the 5-year overall survival rate of breast cancer patients using data from a single institution. The evaluation of a healthcare centre's cancer care performance is relatively new in Malaysia, and this is especially true amongst Malaysian private healthcare centres.

Studies in the past have revealed a lower 5-year overall survival in Asian countries (below 40\%) compared to developed countries $(>80 \%)$. The current study, however, observed a high 5-year overall survival rate of $80.42 \%$ for breast cancer patients from BH. Our finding is in concordance to another single-centre cohort from University of Malaya Medical Centre (UMMC) which have reported an improvement of survival from 58\% to $76 \%$ for patients diagnosed in 1993-1997 compared to 1998$2002 .{ }^{15}$ In fact, our findings on survival rate is similar to the combined report from National University Hospital Singapore (NUHS) and UMMC, which revealed a 5-year overall survival of $30.2 \%$ for stage III and IV patients.

It is generally well accepted that breast cancer rates differ substantially across different ethnic groups. White Americans and Black Americans were reported to have 


\begin{tabular}{|c|c|c|}
\hline Treatment modalities & Early/Locally advanced, $(n=107)$ & Metastatic breast cancer, $(n=36)$ \\
\hline Radiotherapy, n (\%) & $95(88.97)$ & $31(86.11)$ \\
\hline \multicolumn{3}{|l|}{ Site } \\
\hline Breast/Wall & $89(93.7)$ & $15(51.6)$ \\
\hline Others & $6(6.3)$ & $16(48.4)$ \\
\hline \multicolumn{3}{|l|}{ Treatment regime } \\
\hline Curative intent & $88(92.6)$ & \\
\hline Palliative intent & $6(6.3)$ & \\
\hline Unknown & $1(1.1)$ & \\
\hline Systemic Therapy, n (\%) & $107(100)$ & $35(97.2)$ \\
\hline Chemotherapy, n (\%) & $88(82.2)$ & $33(94.3)$ \\
\hline Neo-adjuvant & $2(2.3)$ & \\
\hline Adjuvant & $82(93.2)$ & \\
\hline Neo-adjuvant and adjuvant & $3(3.4)$ & \\
\hline Unknown & $1(1.1)$ & \\
\hline Hormonal Therapy, n (\%) & 77 (71.96) & $21(60)$ \\
\hline Oestrogen Receptor Antagonist Tamoxifen & $57(74.0)$ & $11(31.4)$ \\
\hline \multicolumn{3}{|l|}{ Aromatase Inhibitor } \\
\hline Letrozole & $16(20.8)$ & $12(34.3)$ \\
\hline Anastrozole & $16(20.8)$ & $8(22.9)$ \\
\hline Exemestane & $3(3.9)$ & $6(17.2)$ \\
\hline GnRH ag (Goserelin Acetate) & $4(5.2)$ & $2(5.7)$ \\
\hline Progestogens & 0 & 0 \\
\hline Anti-androgens & 0 & 0 \\
\hline Leuprorelin Acetate & 0 & $1(2.9)$ \\
\hline Targeted Therapy, n (\%) & $22(28.6)$ & $14(40)$ \\
\hline Trastuzumab & $22(28.6)$ & $11(31.4)$ \\
\hline Pertuzumab & 0 & 0 \\
\hline Trastuzumab-emtansine & 0 & $2(5.7)$ \\
\hline Lapatinib & $2(2.6)$ & $11(31.4)$ \\
\hline \multicolumn{3}{|l|}{ No Treatment, n (\%) } \\
\hline HER2 positive & $6(21.4)$ & $3(21.4)$ \\
\hline All types & $8(7.5)$ & $4(11.1)$ \\
\hline
\end{tabular}

a higher breast cancer incidence rate when compared to Hispanic women and Asian women. The same findings have also been demonstrated on Malaysian women, comprising of the 3 most populous ethnic groups in Asia, where Malay women were reported to have significantly higher risk of all-cause mortality, independent of age, stage, tumour characteristics and treatment compared to Indian and Chinese ethnic group. ${ }^{11,16}$ However, the current study did not find significant disparity in the 5-year overall survival when patients were compared by ethnic groups. Similarly, when patients were categorized by age groups, there was no significant difference in the 5-year overall survival. This is in contrast to previous findings, where post-menopausal patients were observed to have better survival whilst younger patients tend to have poor survival. ${ }^{17,18}$

Triple-negative breast cancer (TNBC) is a sub-category of breast tumour which lacks the expression of the three most commonly targeted biomarkers considered for breast cancer treatment, namely oestrogen receptor (ER), progesterone receptor (PR) and human epidermal growth factor receptor (HER2). ${ }^{19}$ TNBC accounts for $15-20 \%$ if all breast cancer diagnoses and is usually associated with more aggressive clinical course, worse evolution within the first 3 to 5 years after diagnosis; early and higher rates of distant visceral metastasis compared to other breast cancer subtypes, as well as poor survival. ${ }^{19-22}$ As the TNBC subtype is commonly associated with poor prognosis, the present study evaluated the 5-year overall survival of this group of patients and reported a 76\% 5-year overall survival, with the mean time to death of 4.5 years $(4.015$ to 4.977$)$. This is in concordance to previous findings which reported a $68 \%-82 \% 5$-year survival for TNBC patients. ${ }^{23-25}$ TNBC patients are four times more likely to develop visceral metastases in contrast to non-TNBC subtype. ${ }^{26}$ In addition, the treatment decision for metastatic TNBC is also challenging due to the lack of targeted therapy. Therefore, we also further evaluated the 5-year overall survival of TNBC patients based on the presence of metastasis. Here, TNBC patients without metastasis recorded a $100 \% 5$-year overall survival, in contrast to only a $40 \%$ survival for those with the presence of metastases. The finding from this study compares favourably to studies conducted in Taiwan and Peru which reported a $26.5 \%$ and $26 \% 5$-year overall survival for TNBC patient 

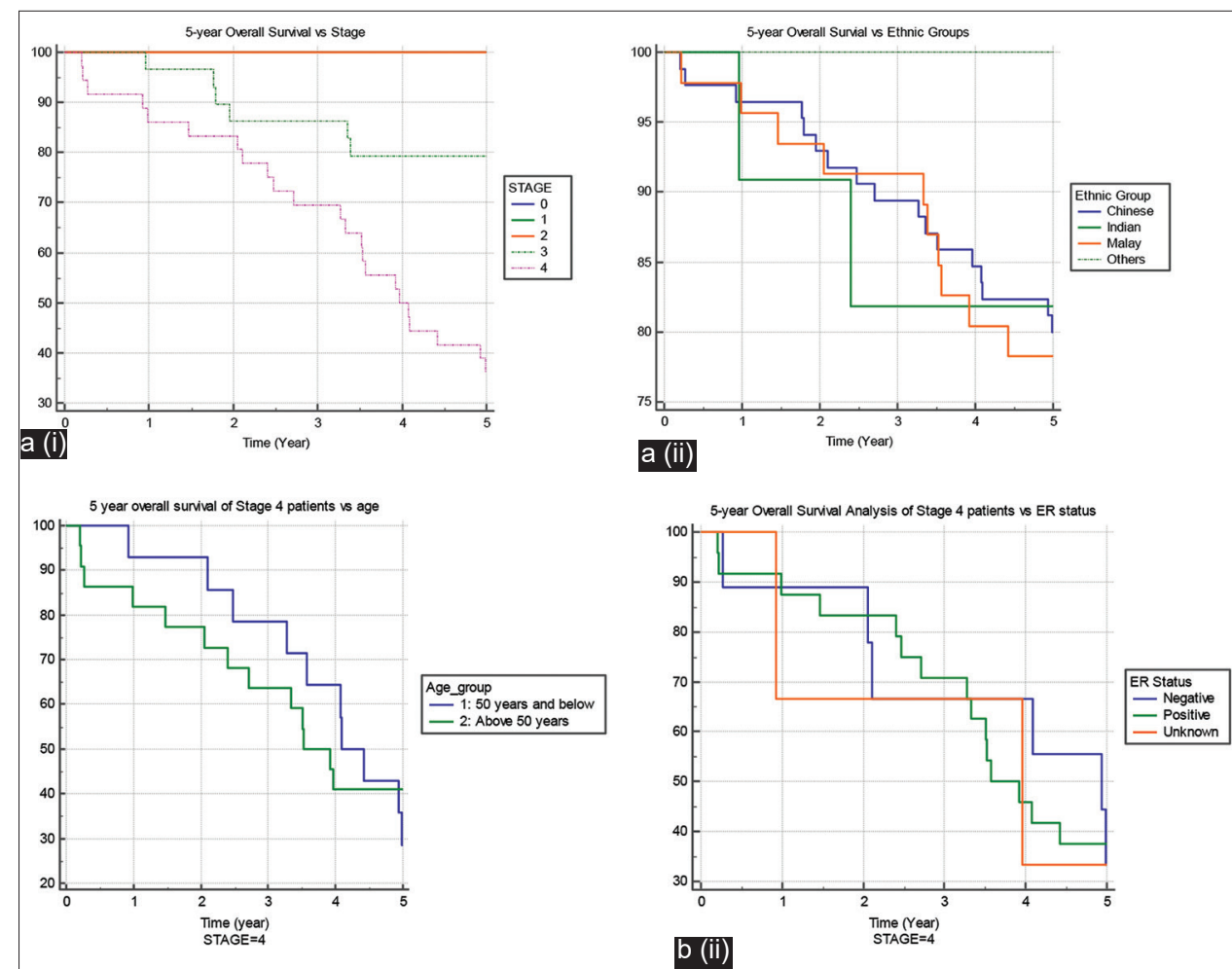

b(i)

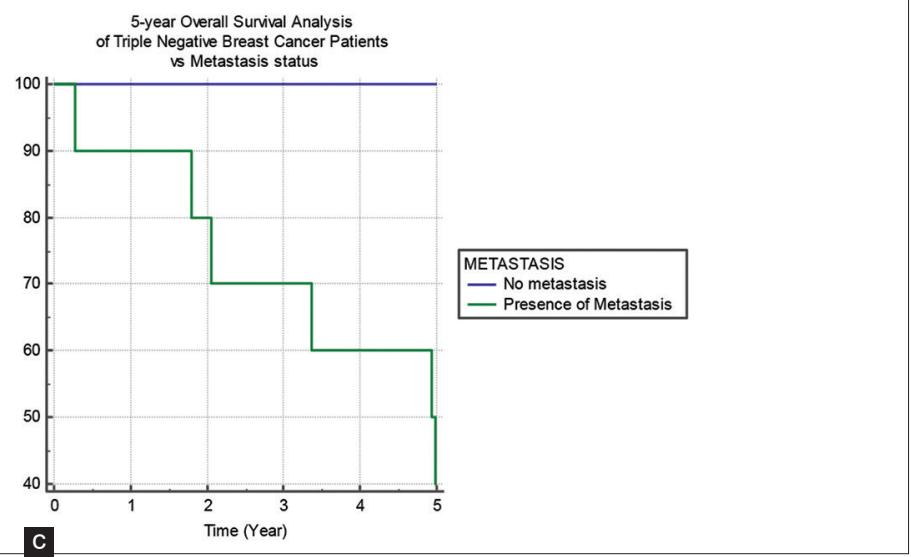

Figure 1: Kaplan-Meier 5-year overall survival analysis. 5-year survival analysis of breast cancer patients stratified by (a (i)) stage, (a (ii)) ethnicity; 5-year survival analysis of Stage 4 breast cancer patients stratified by (b (i)) age; (b (ii)) ER status; (c) 5-year overall survival analysis of breast cancer patients with triple negative subtype stratified by status of metastases. Triple negative patients without the presence of metastasis has a significantly better survival in contrast to those with the presence of metastases $(p=0.0004)$

with metastasis respectively. ${ }^{27,28}$ In support of this notion, another study from the US has also reported greater than $75 \%$ breast cancer-specific mortality for TNBC patients who experienced distant recurrence. ${ }^{29}$

One obvious limitation of this study is that this is a single-institution-based studies and that the small number of patients investigated could not be a representation of the management and outcome of breast cancer in Malaysia. The small number of patients have also limited the statistical power of some analyses and were insufficient to reach definitive conclusions. We were also not able to evaluate the influence of covariates such as the histopathology subtypes, the presence of hormone receptors and the type of treatment on the survival rate. In addition to that, it is difficult to determine the direct or indirect cause of death related to breast cancer. Despite these limitations, this study provides an encouraging RWD result on breast cancer survival for a relatively new cancer centre in Malaysia.

In conclusion, the overall 5-year survival rate of breast cancer patients amongst Malaysian women who sought treatment in BH from 2008-2012 compares favourably to the survival data of North America and Oceania at $84 \%$. Findings from the present study will be useful in assisting advocacy organisations to provide information about resources and support as well as to raise awareness. 


\section{ACKNOWLEDGEMENTS}

We thank the Medical Records department for facilitating the medical records retrieval and tracing the present status of the patients.

\section{REFERENCES}

1. Jemal A, Bray F, Center MM, Ferlay J, Ward E and Forman D. Global cancer statistics. CA Cancer J Clin 2011;61(2):69-90.

2. Hirabayashi $Y$ and Zhang M. Comparison of time trends in breast cancer incidence (1973-2002) in Asia, from cancer incidence in five continents, Vols IV-IX. Jpn J Clin Oncol 2009;39(6):411-412.

3. Sim X, Ali RA, Wedren S, Goh DL, Tan CS, Reilly M, et al. Ethnic differences in the time trend of female breast cancer incidence: Singapore, 1968-2002. BMC Cancer 2006;6:261.

4. Ravdin PM, Cronin KA, Howlader N, Berg CD, Chlebowski RT, Feuer EJ, et al. The decrease in breast-cancer incidence in 2003 in the United States. N Engl J Med 2007;356(16):1670-1674.

5. Hawkes N. Cancer survival data emphasise importance of early diagnosis. BMJ. 2019;364:1408.

6. Fejerman L and Ziv E. Population differences in breast cancer severity. Pharmacogenomics 2008; 9(3):323-333.

7. Coleman MP, Quaresma M, Berrino F, Lutz JM, De Angelis R, Capocaccia $R$, et al. Cancer survival in five continents: a worldwide population-based study (CONCORD). Lancet Oncol 2008;9(8):730-756.

8. Ferlay J, Soerjomataram I, Dikshit R, Eser S, Mathers C, Rebelo $\mathrm{M}$, et al. Cancer incidence and mortality worldwide: sources, methods and major patterns in GLOBOCAN 2012. Int J Cancer 2015;136(5):E359-386.

9. Pathy NB, Yip CH, Taib NA, Hartman M, Saxena N, lau P, et al. Breast cancer in a multi-ethnic Asian setting: results from the Singapore-Malaysia hospital-based breast cancer registry. Breast 2011;20 Suppl 2:S75-S80.

10. Taib NA, Akmal M, Mohamed I and Yip CH. Improvement in survival of breast cancer patients - trends over two time periods in a single institution in an Asia Pacific country, Malaysia. Asian Pac J Cancer Prev 2011;12(2):345-349.

11. Al-Naggar RA, Isa ZM, Shah SA, Nor MI, Chen R, Ismail F, et al. Eight year survival among breast cancer Malaysian women from University Kebangsaan Malaysia Medical Centre. Asian Pac J Cancer Prev 2009;10(6):1075-1078.

12. Youlden DR, Cramb SM, Yip CH and Baade PD. Incidence and mortality of female breast cancer in the Asia-Pacific region. Cancer biology and Medicine 2014;11(2):101-115.

13. Ghoncheh $M$, Momenimovahed $Z$ and Salehiniya $H$. Epidemiology, Incidence and Mortality of Breast Cancer in Asia. Asian Pac J Cancer Prev 2016;17(S3):47-52.

14. Sharma R. Breast cancer incidence, mortality and mortality-toincidence ratio (MIR) are associated with human development,
1990-2016: evidence from Global Burden of Disease Study 2016. Breast Cancer 2019; 26 (4):428-445.

15. Taib NA, Yip CH, Ibrahim M, Ng CJ and Farizah H. Breast cancer in malaysia: are our women getting the right message? 10 yearexperience in a single institution in Malaysia. Asian Pac J Cancer Prev. 2007;8(1):141-145.

16. Bhoo-Pathy $\mathrm{N}$, Hartman M, Yip C-H, Saxena N, Taib NA, Lim S-E, et al. Ethnic Differences in Survival after Breast Cancer in South East Asia. PLOS ONE 2012;7(2):e30995.

17. Kataoka A, Iwamoto T, Tokunaga E, Tomotaki A, Kumamaru H, Miyata $\mathrm{H}$, et al. Young adult breast cancer patients have a poor prognosis independent of prognostic clinicopathological factors: a study from the Japanese Breast Cancer Registry. Breast Cancer Res Treat. 2016;160(1):163-172.

18. Yoshimura $A$ and Ito $H$. Recent Improvement in the Long-term Survival of Breast Cancer Patients by Age and Stage in Japan 2018; 28(10):420-427.

19. Anders CK, Abramson V, Tan T and Dent R. The Evolution of Triple-Negative Breast Cancer: From Biology to Novel Therapeutics. Am Soc Clin Oncol Educ Book 2016;35:34-42.

20. Kennecke H, Yerushalmi R, Woods R, Cheang MCU, Voduc D, Speers CH, et al. Metastatic Behavior of Breast Cancer Subtypes. Journal of Clinical Oncology 2010;28(20):3271-3277.

21. Heitz F, Harter P, Lueck HJ, Fissler-Eckhoff A, Lorenz-Salehi F, Scheil-Bertram S, et al. Triple-negative and HER2-overexpressing breast cancers exhibit an elevated risk and an earlier occurrence of cerebral metastases. Eur J Cancer 2009;45(16):2792-2798.

22. Foulkes WD, Smith IE and Reis-Filho JS. Triple-negative breast cancer. N Engl J Med 2010;363(20):1938-1948.

23. van Roozendaal LM, Smit LHM, Duijsens GHNM, de Vries B, Siesling S, Lobbes MBI, et al. Risk of regional recurrence in triple-negative breast cancer patients: a Dutch cohort study. Breast Cancer Res Treat. 2016; 156(3):465-472.

24. Ovcaricek T, Frkovic SG, Matos E, Mozina B and Borstnar S. Triple negative breast cancer - prognostic factors and survival. Radiology and oncology 2010;45(1):46-52.

25. James $M$, Dixit A, Robinson B, Frampton $C$ and Davey V. Outcomes for Patients with Non-metastatic Triple-negative Breast Cancer in New Zealand. Clinical Oncology 2019;31(1):17-24.

26. Dent $R$, Hanna WM, Trudeau M, Rawlinson $E$, Sun $P$ and Narod SA. Pattern of metastatic spread in triple-negative breast cancer. Breast Cancer Res Treat 2009;115(2):423-428.

27. Morante Z, Ku GADIC, Enriquez D, Saavedra A, Luján $M$, Luque $R$, et al. Post-recurrence survival in triple negative breast cancer. Journal of Clinical Oncology 2018; 36(15_ suppl):e13120-e13120.

28. Tseng LM, Hsu NC, Chen SC, Lu YS, Lin CH, Chang DY, et al. Distant metastasis in triple-negative breast cancer. Neoplasma 2013;60(3):290-294.

29. Steward L, Conant L, Gao F and Margenthaler JA. Predictive Factors and Patterns of Recurrence in Patients with Triple Negative Breast Cancer. Annals of Surgical Oncology 2014;21(7):2165-2171.

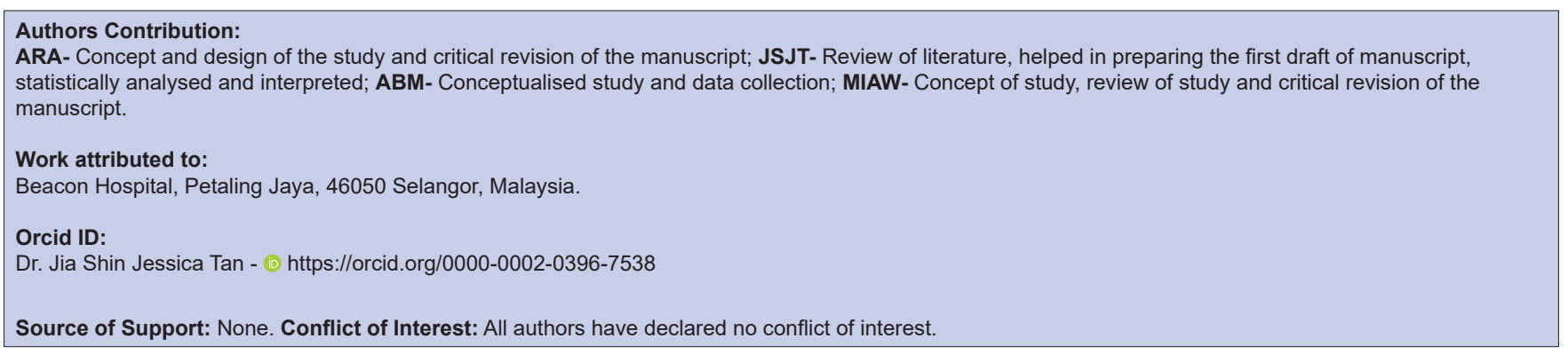

